\title{
Role of computed tomography in the diagnosis of solitary pulmonary nodule with solid component: a narrative review
}

\author{
Paola Franchi ${ }^{1}$, Luca Procaccini ${ }^{1,2}$, Erica Mincuzzi ${ }^{1,2}$ \\ ${ }^{1}$ Department of Radiology, “G. Mazzini” Hospital, Teramo, Italy; ${ }^{2}$ Department of Neuroscience and Imaging and Clinical Sciences, Institute of \\ Radiology, Section of Diagnostic Imaging and Therapy-Radiology Division, “G. d'Annunzio” University, Chieti-Pescara, Italy \\ Contributions: (I) Conception and design: P Franchi; (II) Administrative support: P Franchi; (III) Provision of study materials or patients: L \\ Procaccini, E Mincuzzi; (IV) Collection and assembly of data: L Procaccini, E Mincuzzi; (V) Data analysis and interpretation: All authors; (VI) \\ Manuscript writing: All authors; (VII) Final approval of manuscript: All authors. \\ Correspondence to: Paola Franchi. Department of Radiology, “G. Mazzini” Hospital, Teramo, Italy. Email: paola.franchi@aslteramo.it.
}

\begin{abstract}
Objective: The aim of this paper is reviewing the role of computed tomography (CT) in the diagnosis and management of solitary pulmonary nodules (SPNs) with solid component, namely solid and partially solid nodules.

Background: The topic is of great interest because the number of pulmonary nodules identified has dramatically raised over time, as a consequence of the increased use of CT in medical care and the diffusion of screening programs.

Methods: MEDLINE and PubMed search was conducted from 2000 through June 2021 using as keywords: "lung cancer", "computed tomography", pulmonary nodule", "solid nodule" and "partially solid nodule".

Conclusion: Size and growth rate assessed by baseline CT and eventual control are the main determinant for management according to guidelines issued by all thoracic society. Most recent guidelines on this topic are summarized. In addition, CT morphological aspects may help the characterization of a nodule, in terms of benignity/malignancy and therefore suggesting a closer or longer follow-up (FUP) or a more invasive diagnostic procedure. Nowadays and in the near future, artificial intelligence (AI) algorithms have the potential to assist radiologists in the difficult task of detecting but also in diagnosing pulmonary nodules, in terms of lesion's volumetry and characterization. This narrative review provides an overview on the role of CT in the evaluation of SPNs with solid component, mainly based on size and growth rate but also on morphological benign and/or malignant features that a radiologist should recognized in order to allow an early diagnosis and a prompt intervention in case of a malignancy and to avoid unnecessary CT FUP or invasive procedures for benign nodules.
\end{abstract}

Keywords: Lung cancer; computed tomography (CT); solid nodule; partially solid nodule

Received: 21 June 2021; Accepted: 08 March 2022; Published: 30 September 2022.

doi: 10.21037/asj-21-52

View this article at: https://dx.doi.org/10.21037/asj-21-52

\section{Introduction}

The detection and definition of malignancy of lung nodules still represent a challenge. Considering that lung cancer is the major cause of death worldwide principally due to the advanced stage of disease at time of diagnosis $(1,2)$, it is important to ensure early diagnosis and timely therapeutic intervention (3). On the other hand, it is essential to minimize false positive results in order to avoid unnecessary follow-up (FUP) or invasive procedures in subjects with benign nodules (3). Thus, several international societies dealing with thoracic diseases constantly update guidelines for lung nodules management (4-6).

The topic is of great interest because the number of pulmonary nodules identified has dramatically raised over time, as a consequence of the increased use of computed 

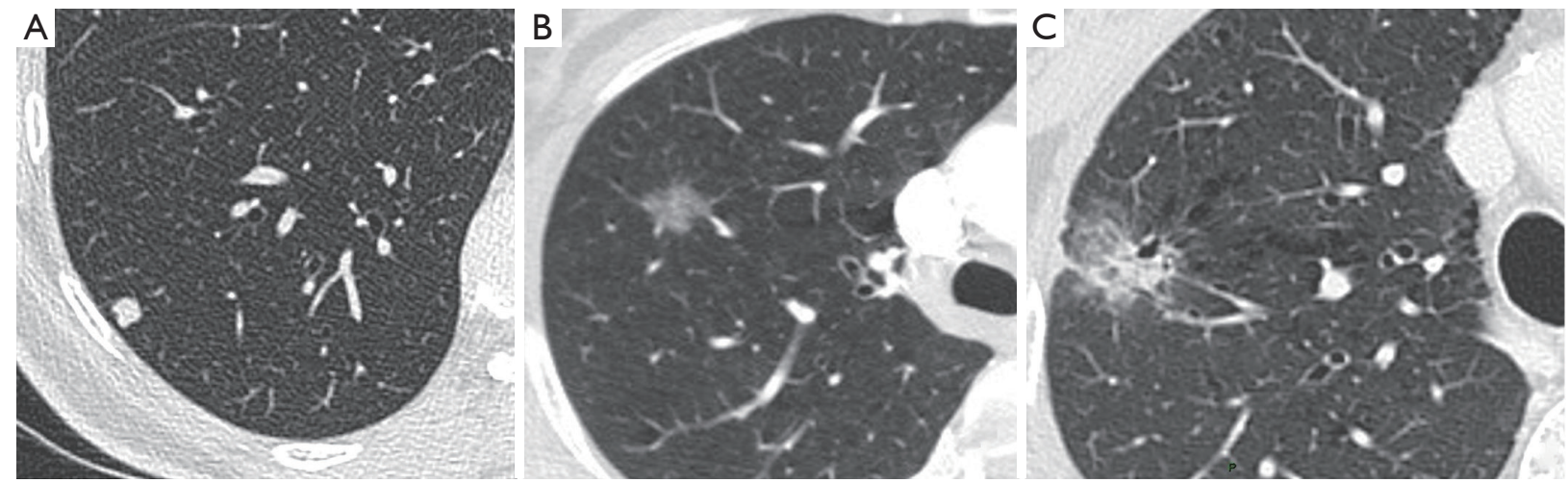

Figure 1 Three axial CT scan magnifications in lung window setting showing different types of nodules according to attenuation. The scans show a solid nodule characterized by a focal area of homogenous soft-tissue attenuation (A), a ground-glass nodule identified by a hazy increased lung attenuation which does not obliterate the vascular and bronchial structures (B), a partially solid nodule containing both solid and non-solid components (C). In the context of the partially solid nodule (C), there is a small area of low density representing a bubble-like lucency or "pseudocavitation".

tomography (CT) in medical care and the diffusion of screening programs that lead to a significantly reduced mortality for lung cancer in screened population in the major randomized controlled trials (RCTs) in US and Europe [respectively up to $20 \%$ in the National Lung Screening Trial (NLST) compared to conventional chest radiograph, up to $24 \%$ for man and $33 \%$ for women compared to non-screened population in Dutche-Belgian Lung Cancer Screening NELSON (Nederlands-Leuvens Longkanker Screenings ONderzoek) trial] $(2,7)$.

Various other smaller RCTs have also reported evidence for the beneficial effects of screening, such as the German Lung cancer Screening Intervention (LUSI) (8), the ITALUNG (9), the DANTE and the Multicentric Italian Lung Detection (MILD) trials $(10,11)$ but were underpowered.

A mean prevalence of $13 \%$ (range, 2-24) has been reported for incidentally detected nodules and even higher of $33 \%$ (range, 17-53) in high-risk screening population, however corresponding to a low mean prevalence of lung cancer respectively of $1.5 \%$ (range, $0-4.0$ ) and $1.4 \%$ (range, $0.5-2.7)(4)$.

A Solitary Pulmonary Nodule (SPN) is described as rounded or irregular opacity, well or poorly defined, with diameter $\leq 3 \mathrm{~cm}$ (12). SPN may be identified on chest radiography or computed tomography (CT). Pulmonary nodules can be discovered incidentally, in the course of screening trials and programs, during staging and FUP of oncological patients. SPNs should be classified according to nodule attenuation in solid and subsolid.

Subsolid nodules include pure ground glass (GG) and partially solid nodules (PSNs). Solid nodule is considered as a focal opacity of homogenous soft-tissue density (Figure 1A), whilst GG nodule presents a hazy increased lung attenuation which does not obliterate the vascular and bronchial structures (12) (Figure 1B); PSN contains both solid and non-solid components (12) (Figure 1C). A different probability of malignancy has been found according to attenuation. The majority of information on nodule's characteristics derived from lung cancer screen programs that are largely diffuse worldwide in recent years. Lung cancer screening experiences reported a higher malignancy for PSNs, followed by GG nodules and solid nodules. In detail, the Early Lung Cancer Action Project (ELCAP) documented malignancy in $63 \%$ of PSNs, in $18 \%$ of GG nodules and in 7\% of solid nodules (13). The data set in the Pan-Canadian Early Detection of Lung Cancer Study (PanCan) and the data set at the British Columbia Cancer Agency (BCCA) found malignancy respectively in 6.6\% and $22.2 \%$ of PSNs, in $1.9 \%$ and $1.3 \%$ of GG nodules, and in $1.1 \%$ and $0.6 \%$ of solid nodules (14).

However, it is necessary to consider that these percentages on PSNs are likely to be overestimated as a disproportionate number (up to half) of the PSNs found in these studies were larger than $10 \mathrm{~mm}$ compared to $<10 \%$ in "positive" solid nodules.

The aim of this paper is to examine the SPNs with solid component, namely solid and partially solid nodules (pure GG nodules are discussed elsewhere in this editorial), and discuss separately their CT characteristics in order to recognize key radiological features suggesting a benign or 


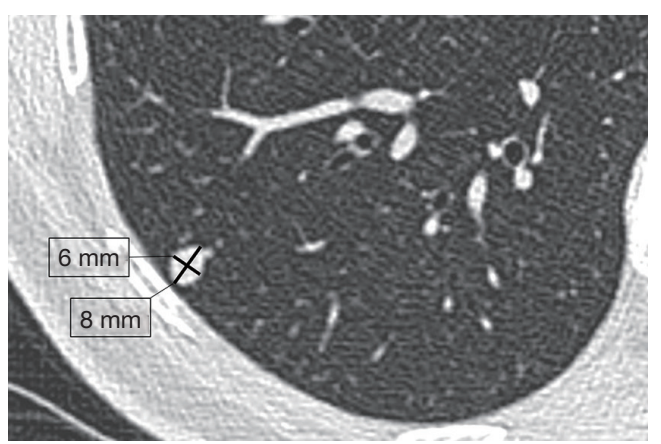

Figure 2 Measurement of a solid nodule with diameter less than $10 \mathrm{~mm}$ according to the Fleischner Society recommendations. Dimension should be expressed as the average of the long- and short-axis diameters both of which obtained in the same plane to reduce measurement variability. The small solid nodule shown have a mean diameter of $7 \mathrm{~mm}$.

malignant cause aiming at reducing unnecessary diagnostic and therapeutic procedure on one hand and perform a timely definitive intervention on the other. We present the following article in accordance with the Narrative Review reporting checklist (available at https://asj.amegroups.com/ article/view/10.21037/asj-21-52/rc).

\section{Methods}

MEDLINE and PubMed were used to search for eligible articles using the terms "lung cancer", "computed tomography", "pulmonary nodule", "solid nodule" and "partially solid nodule" from 2000 through June 2021. In order to allow more extensive research and include all potentially useful papers, we consider variations of the key words such as "lung nodule", "part-solid nodule", "subsolid nodule". Search terms were combined with either "OR" or "AND". A Google cross-search and a hand search using reference lists of published articles were also conducted.

We selected only already published English language medical literature. All types of study design were eligible for inclusion. More than 900 articles were initially selected by two independent physicians in the fields of pulmonary care, hospital medicine and radiology.

Articles were eligible for inclusion if they investigated lung nodule detection and characterization in CT, involved radiologists (expert viewers) or radiology registrars.

Search results were filtered based on title and abstract, at first. Only relevant papers identified by substantial methodology, consistent results and completeness of information were used in the following manuscript.

\section{Discussion}

\section{Solid nodules}

Concerning solid nodules, a long list of differential diagnosis may be assessed, in particular, different benign lesions, such as infections, congenital, traumatic, inflammations, vascular and malignant causes (primary and/or secondary neoplasms) have to be included (15). Several predictors of malignancy have been described and they are divided into clinical (age, smoking history, exposure to asbestos/uranium/radium, idiopathic pulmonary fibrosis, emphysema and history of neoplasms) and radiological (size, attenuation, morphology, margins, location, internal characteristics and growth rate).

Among these risk factors, nodule diameter and growth rate are widely evaluated to assess the probability of malignancy $(4,5,16,17)$. As regards the size, it has been known from literature that there is a proportional rise of malignancy risk as the diameter of the nodule increased $(14,18)$.

The estimated risk of cancer $\geq 1 \%$ in a nodule represent the lowest threshold size for recommending FUP (13). In the Fleischner Society guidelines the minimum threshold size for FUP is $6 \mathrm{~mm}$ (5). Horeweg et al., instead, calculated lung cancer probabilities in NELSON screening population, stratified by nodule diameter, volume, and volume doubling time (VDT) (19). Pulmonary tumor likelihood was low in subjects with a nodule volume of $100 \mathrm{~mm}^{3}$ or smaller, or maximum transverse diameter $<5 \mathrm{~mm}$, or VDT $>600$ days. It was intermediate (requiring FUP CT) if nodules had a volume of $100-300 \mathrm{~mm}^{3}$ or a diameter $5-10 \mathrm{~mm}$ or VDT $>400$ and $\leq 600$ days and higher for subjects with nodule volumes $\geq 300$ $\mathrm{mm}^{3}$ or diameters $\geq 10 \mathrm{~mm}$ or VDT $\leq 400$ days (19). Therefore 5 or $6 \mathrm{~mm}$ are the cut-off points above which consider a nodule actionable ("one judged by the radiologist to require further evaluation") as stated by the British Thoracic Society (BTS) guidelines (mainly based on NELSON lung cancer screening trial) and Fleischner Society guidelines for incidentally found nodules respectively $(4,5)$. As the disposable guidelines for nodule management are mainly based on nodule size or its growth, it is pivotal to correctly measure nodule dimensions. SPN size and its change can be defined by measuring the diameter or volume, in particular Fleischner Society guidelines are based on diameter while BTS guidelines are mostly based on volume.

According to Fleischner Society recommendations for 

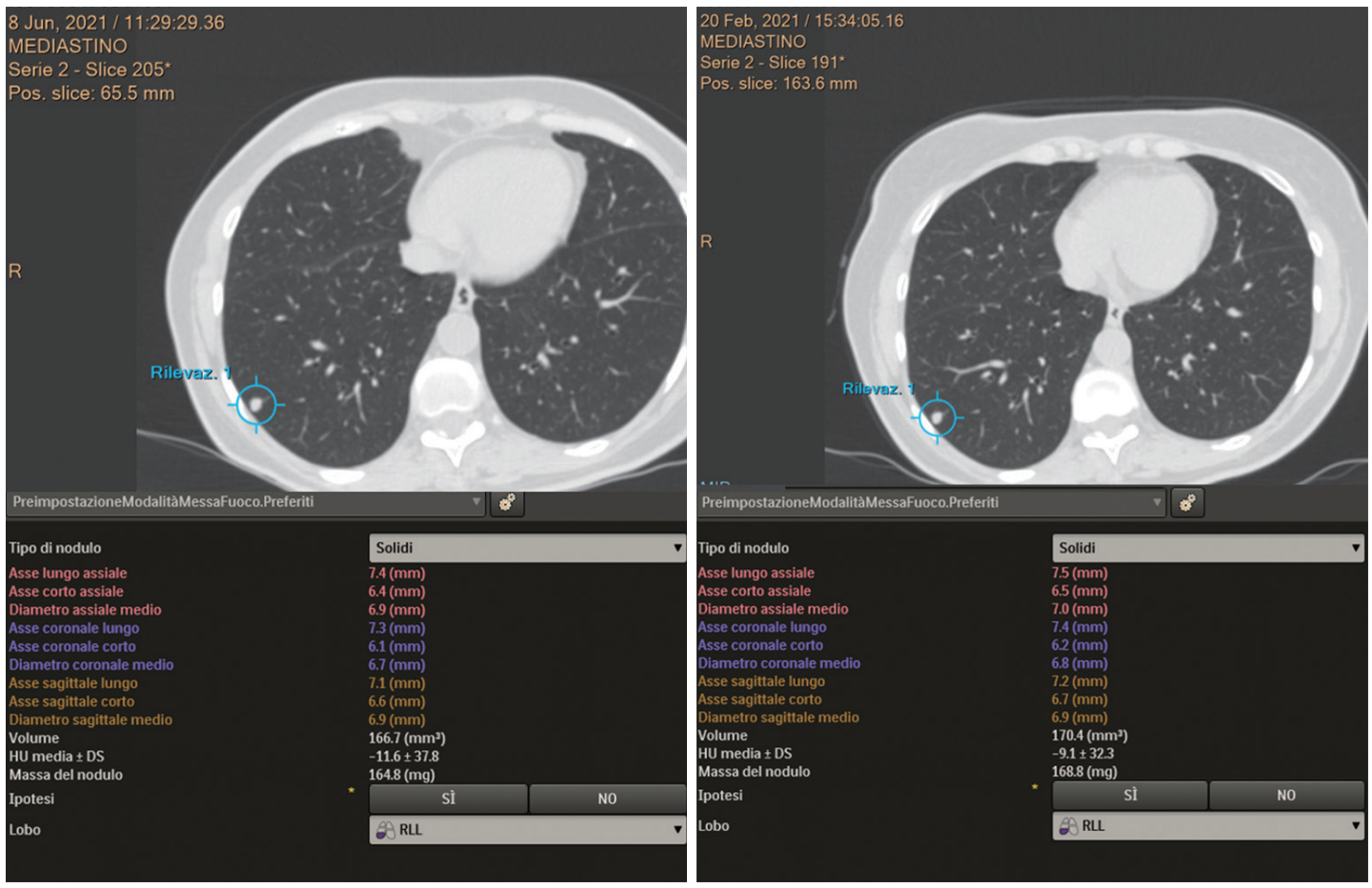

Figure 3 Imaging of a routine clinical care software used for the calculation of volume doubling time after three months of a small solid nodule. In particular, the software calculated both long- and short-axis diameters in axial, coronal and sagittal planes, as well as the volume and the mass in the two CT examinations (baseline on the right and control at three months on the left) counting also the volume doubling time. The control did not reveal significant changes in the volume of the nodule, which means a high probability of benignity.

solid nodules with diameter less than $10 \mathrm{~mm}$, dimension should be expressed as the average of the long- and short-axis diameters, both obtained in the identical plane (Figure 2), to reduce measurement variability because it is assumed that the average diameter presumable correlates better with $3 \mathrm{D}$ tumor volume rather than one measurement, particularly in not perfectly round nodules (20). For larger nodules, measurements reporting both long- and short-axis diameter are preferred (20). Measurement should be carried out on axial scans, however, if the maximal dimensions lie in a coronal or sagittal plane, the measurement should be performed in those planes and documented in the radiological report (20).

SPN volumes may be measured by delineating nodule boundaries (manually) or by using software that identifies CT density thresholds (semiautomatically) (20) (Figure 3).

In NELSON trial maximum diameter was measured in three planes in order to calculate VDT (19).

Even if diameter measurement is usually performed in clinical practice, limitations of cross-sectional measurement are widely recognized. Measurements with electronic calipers are subject to variability and variability grows with the growing complexity of SPN morphology (21). Moreover, diameter measurements modify by $1.73 \mathrm{~mm}$ among different raters meaning that are unreliable for small nodules (22).

Volume measurements allow evaluation of irregular nodules and the eventual asymmetrical growth (23). Volume evaluation has a high intra- and inter-reader agreement with high sensitivity in detecting abnormal growth at short interval time (24). Volumetry optimizes nodule stratification and management (25).

A VDT $\leq 400$ days is considered the cut-off for malignancy (24). Anyhow, also volumetry has limitations, in particular interscan variability may be due to segmentation algorithm, acquisition/reconstruction parameters (slice thickness, kernel), nodule size and morphology, temporal resolution (inspiration level, motion artifacts) (26).

In a study by Tammemagi et al. based on screendetected lung nodules (27) both mean diameter and volume models (using computer-aided detection and radiologist measurements) showed excellent performance of nodule 


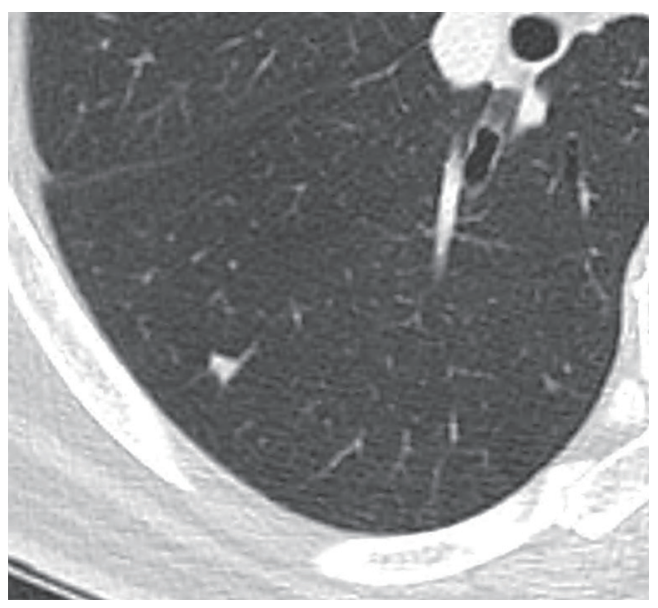

Figure 4 Magnification of an axial CT scan at parenchymal window setting showing a $9 \mathrm{~mm}$ solid nodule in the right lower lobe in a subpleural location with a triangular/polygonal shape, smooth outline and characterized by extending linear density (corresponding to an interlobular septum) representing with very high probability an intrapulmonary lymph node.

malignancy risk prediction with similar areas under the receiver operating characteristic curves of 0.947 .

As regards changes in size, a $2-\mathrm{mm}$ threshold for growth was assumed conventionally by both BTS and Fleischner Society guidelines in the recent management recommendations $(4,20)$. Smaller changes in greater diameter can be spurious and do not reliably indicate change.

Similarly, a volume change inferior to $25 \%$ is not considered significant (26).

Proper CT-scan technique is thus necessary. Thin sections $(\leq 1.5 \mathrm{~mm})$, high-spatial-frequency kernel (sharp) and window level setting $(-600 / 1,600 \mathrm{HU})$ are required. However, for nodules $\geq 10 \mathrm{~mm}$ kernel has not substantial effect on nodule measurement (20).

As regards shape and location, a nodule with lentiform, triangular, or polygonal shape, smooth outline, with a maximum diameter up to $12 \mathrm{~mm}$, adjacent to the pleura on or within $10-15 \mathrm{~mm}$ of the visceral pleura/fissures, with a lack of arterial attachment whilst often showing an interlobular septal connection (where the lymphatics run), has a high probability to represent a benign lesion and in particular an intrapulmonary lymph node, both in lung cancer-screening setting and in routine care (28-34). The term "perifissural nodule" was coined to represent the typical CT features of an intrapulmonary lymph node (24)
(Figure 4), which does not require FUP (28-34).

On the other hand, spiculation, irregular shape, unsharp borders, distortion of the pleura/fissure, fissural transgression represent morphological characteristics suggesting a different nature of a nodule, other than an intrapulmonary lymph node and need FUP (28-30).

Margins are not a good predictive factor because smooth margins are associated to a prevalence of malignancy of $20 \%$ to $30 \%$ and lobulated, irregular or spiculated margins (Figure 5) have a wide prevalence of malignancy ranging between $33 \%$ to $100 \%$ (30). There is agreement in considering spiculated margins as mostly associated to malignancy with a predictive positive value of $90 \%$ and to scarce prognosis, owing to the high probability of having lymph node metastasis and vascular invasion; spiculation (often described as "corona radiata") is likely due to the proliferation of cancerous cells along the lung interstitium, while lobulation is likely due to different growth rates within nodules. Furthermore, attenuation and internal characteristics are useful but not completely reliable criteria for differential diagnosis. Nodules with macroscopic diffuse, central, laminated or popcorn calcifications and with fat tissue component are considered as predictors of a benign etiology (hamartomas, granulomas) (35). Diffuse, amorphous or punctate dystrophic calcifications, few in number and more eccentric in location, are more likely present in malignant SPNs (35). SPNs containing adipose tissue may include the differential diagnosis of metastasis from liposarcoma or renal cell cancer and lipoid pneumonia. Besides, cystic airspaces must be considered as suspicious, above all, in whom with increased wall thickness or nodule emerging in the wall (36).

\section{Partially solid nodules}

PSNs may be solitary or multiple and may have benign causes, like focal inflammation, focal fibrosis or organizing pneumonia, as well as malignant causes, mostly represented by peripheral adenocarcinoma and rarely by metastases (melanoma, renal cell carcinoma, and adenocarcinoma of the pancreas, breast, and gastrointestinal tract; lymphoproliferative disorders) (37). PSNs are distinguished into transient, which spontaneously resolve, and persistent. Transient PSNs are more frequent in male young people, smokers, patients with eosinophilia and often they are illdefined with a large solid component (15). When a previous CT is available, they are usually absent (38).

Persisting PSNs may be related to focal fibrosis or 

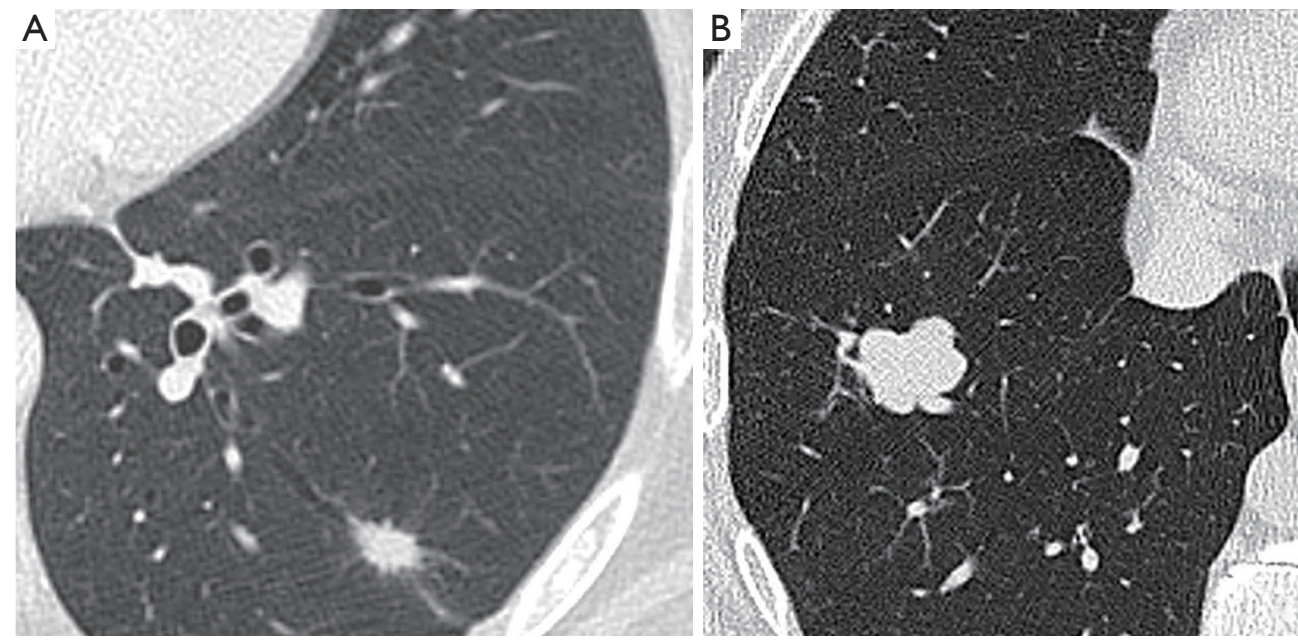

Figure 5 Magnifications of axial CT scans at parenchymal window setting showing (A) a solid nodule with spiculated margins and pleural tag and (B) a solid nodule characterized by lobulated margins. The two nodules were resected, and the histological analysis revealed lung cancer in both.

mucose-associated lymphoid tissue (MALT) lymphoma in a small percentage of cases but in most cases, they represent lung adenocarcinoma (15).

Among the adenocarcinomatous lesions, PSNs are nowadays pathologically classified into adenocarcinoma in situ (AIS), minimally invasive adenocarcinoma (MIA) and invasive adenocarcinoma (39). Adenocarcinoma may show both the GG component which typically represents a lepidic pattern, associated to a good prognosis, and the solid component, which is associated to a poor prognosis, with an invasive growth pattern. In a study by Cohen $e t$ al., which included only PSNs pathologically confirmed to be adenocarcinomas, therefore compatibly with the bias of considering only a small subgroup of PSNs, risk of invasiveness depends on solid portion: if it exceeds $5 \mathrm{~mm}$, it has $100 \%$ sensitivity for invasiveness, whilst a solid portion $<3 \mathrm{~mm}$ has $100 \%$ specificity for pre-invasive lesion (40).

Clinical predictors of malignancy are superimposable to those of solid nodule, but they are not determinant for differential diagnosis.

Among the radiological features of likelihood of malignancy, size and growth rate play an essential role, as well as to solid nodule.

A routine FUP is not recommended for solitary PSNs $<6 \mathrm{~mm}$ (5). As a matter of fact, a distinct solid component may not be identified with security in such tiny nodules, and it is better to treat these lesions like pure GG nodules of analogous diameter (5).
For solitary PSNs $\geq 6 \mathrm{~mm}$ with a solid component $<6 \mathrm{~mm}, \mathrm{FUP}$ is advised at 3-6 months and subsequently every year for a minimum of 5 years. Albeit persistent PSNs likely represent malignancy, PSNs with a solid component $<6 \mathrm{~mm}$ constitute usually either AIS or MIA rather than invasive adenocarcinoma $(40,41)$. These statements only apply to a minority of nodules which had been resected based on subjective factors in the medical decision-making process, however, in these cases a FUP documenting stability is preferred respect to intervention.

Moreover, PSNs can represent transitory infections and may disappear after short-term FUP (42). In fact, in order to define resolution or persistence, 3-6 months FUP scan is advised in the first instance in this kind of lesions. For persistent PSNs, yearly FUP for 5 years is recommended to evaluate unequivocal stability of the solid component (5).

On the other hand, a strict 3-6 months FUP CT scan should be considered to evaluate for persistence of the nodule in case of PSN with a solid component $\geq 6 \mathrm{~mm}$, because of the likelihood of invasive tumor. In addition, even a more invasive diagnostic procedures should be taken into consideration in case of PSNs with particularly suspicious morphology, a growing solid component, or a solid component larger than $8 \mathrm{~mm}(5)$.

Dimensions of both solid and non-solid component should be recorded in the radiological report, in order to document changes in the future (20). As with solid nodules, the average of the long- and short-axis diameters -including GG and cystic 


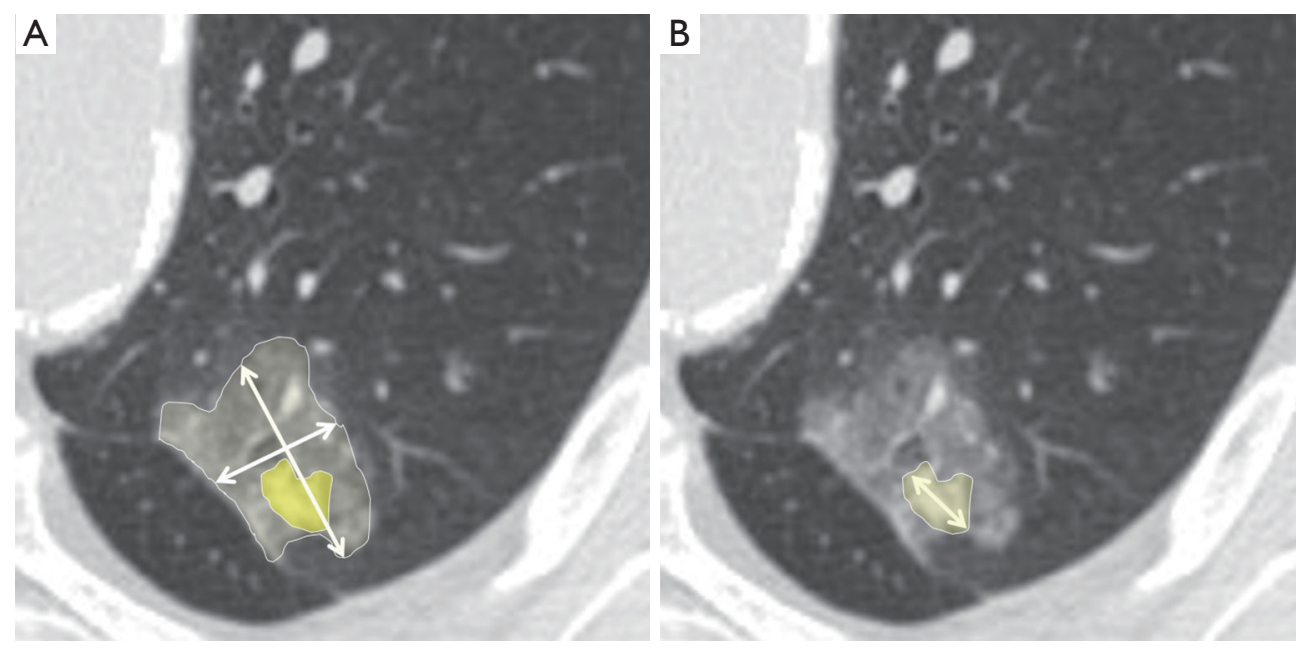

Figure 6 Measurement of a partially solid nodule $\geq 10 \mathrm{~mm}$ according to the Fleischner Society recommendations. Both long- and short-axis diameters of the whole lesion should be recorded (A). On the basis of the clinical implications, the use of the larger long-axis diameter of the solid component is recommended (B).

component- should be measured and recorded for nodules $<10 \mathrm{~mm}$ (20). For nodules $\geq 10 \mathrm{~mm}$, both long- and short-axis diameters of the whole lesion have to be recorded. Because of the solid component is likely to represent the invasive constituent of the lesion pathologically, the use of its larger long-axis diameter on CT is recommended (20) (Figure 6).

As for solid nodules, the increasing in diameter by $2 \mathrm{~mm}$ is considered the minimum threshold for defining growth. However, in PSNs this concept should be applied to overall nodule size as well as to the solid component (20). A new or growing solid component compared with baseline CT, is always highly suspected.

Automated and semi-automated volume measurement for PSNs is less reliable then for solid nodules because of the more difficult segmentation.

In a study by Hasegawa et al., based exclusively on confirmed cancers, VDT is longer for PSNs (457 260 days) with respect to solid nodules (43). Moreover, VDT is longer for PSNs with solid component $\leq 5 \mathrm{~mm}$ (mean VDT $=1,711.2$ days) $v s$. PSNs with solid component $>5 \mathrm{~mm}$ (mean VDT $=717$ days) (44).

For PSNs too there are morphological criteria increasing the suspicious of malignancy (35). As for solid nodules, they include irregular/spiculated margins and pleural retraction $(40,45)$.

Bubble-like lucencies or "pseudocavitation" are small areas of low density maybe due to tiny patent bronchi into the nodule (Figure 1C); it seems that the presence of bubble- like lucencies in PSNs is faintly more common in invasive adenocarcinomas than in preinvasive lesions (45) and it is uncommon in non-cancerous lesions.

\section{Present and future perspectives}

The technological improvements of CT scanners and widespread of lung cancer screening programs have risen the number of incidentally detected lung nodules over the past years, leading to an increase of radiologist's workload. Anyhow, the majority of them remains indeterminate at imaging.

Due to the development of computer engineering in recent years, Artificial Intelligence (AI) has become part of our daily lives. AI based informatics tools are used for imaging analysis, with the aim of aiding radiologist in his work.

In particular, in this context, AI algorithms have been proposed not only to assist radiologists in the difficult task of detecting but also in diagnosing pulmonary nodules, in terms of lesion's volumetry (which includes nodule growth and response to treatment assessment) and characterization, demonstrating a potential supportive role for radiologists when interpreting nodules in chest CT scans (46-50).

However, future studies are necessary and should focus on large-scale validation of novel AI-based algorithms and need to address novel reading paradigms (51).

In conclusion, CT plays a pivotal role in the management of SPNs, that is mainly based on size and growth rate 
according to the most recent guidelines on the topic. BTS guidelines for the investigation and management of pulmonary nodules (mainly based on volume measurements) have been published in 2015 (4), while in 2017 the Fleischner Society guidelines on the current recommendations to proper nodule management have been updated (5).

However, apart from size, it is fundamental to know and recognize malignant features of solid and partially solid nodules, in order to allow an early diagnosis and a prompt intervention in case of a malignancy and to avoid unnecessary CT FUP or invasive procedures for benign nodules.

In this context, physicians should be aware of the increasing power of AI in diagnostic imaging and its potential to enhance and transform the practice of radiology worldwide.

\section{Acknowledgments}

Funding: None.

\section{Footnote}

Provenance and Peer Review: This article was commissioned by the Guest Editors (Duilio Divisi and Roberto Crisci) for the series "Solitary Pulmonary Nodule" published in $A M E$ Surgical fournal. The article has undergone external peer review.

Reporting Checklist: The authors have completed the Narrative Review reporting checklist. Available at https:// asj.amegroups.com/article/view/10.21037/asj-21-52/rc

Peer Review File: Available at https://asj.amegroups.com/ article/view/10.21037/asj-21-52/prf

Conflicts of Interest: All authors have completed the ICMJE uniform disclosure form (available at https://asj.amegroups. com/article/view/10.21037/asj-21-52/coif). The series "Solitary Pulmonary Nodule" was commissioned by the editorial office without any funding or sponsorship. The authors have no other conflicts of interest to declare.

Ethical Statement: The authors are accountable for all aspects of the work in ensuring that questions related to the accuracy or integrity of any part of the work are appropriately investigated and resolved.
Open Access Statement: This is an Open Access article distributed in accordance with the Creative Commons Attribution-NonCommercial-NoDerivs 4.0 International License (CC BY-NC-ND 4.0), which permits the noncommercial replication and distribution of the article with the strict proviso that no changes or edits are made and the original work is properly cited (including links to both the formal publication through the relevant DOI and the license). See: https://creativecommons.org/licenses/by-nc-nd/4.0/.

\section{References}

1. World Health Organization. Cancer. Available online: https://www.who.int/news-room/fact-sheets/detail/cancer. Last updated March 2021. Date last accessed: June 2021.

2. de Koning HJ, van der Aalst CM, de Jong PA, et al. Reduced Lung-Cancer Mortality with Volume CT Screening in a Randomized Trial. N Engl J Med 2020;382:503-13.

3. Larici AR, Farchione A, Franchi P, et al. Lung nodules: size still matters. Eur Respir Rev 2017;26:170025.

4. Callister ME, Baldwin DR, Akram AR, et al. British Thoracic Society guidelines for the investigation and management of pulmonary nodules. Thorax 2015;70 Suppl 2:ii1-ii54.

5. MacMahon H, Naidich DP, Goo JM, et al. Guidelines for Management of Incidental Pulmonary Nodules Detected on CT Images: From the Fleischner Society 2017. Radiology 2017;284:228-43.

6. Kazerooni E, Aberle DR, Black WC et al (2019) Lung RADS ® Version 1. 1 Assessment Categories. Available online: https://www.acr.org/-/media/ACR/Files/RADS/ Lung-RADS/LungRADSAssessmentCategoriesv1-1. pdf?la=en. Accessed June 2021.

7. National Lung Screening Trial Research Team; Aberle DR, Adams AM, et al. Reduced lung-cancer mortality with low-dose computed tomographic screening. $\mathrm{N}$ Engl J Med 2011;365:395-409.

8. Becker N, Motsch E, Trotter A, et al. Lung cancer mortality reduction by LDCT screening-Results from the randomized German LUSI trial. Int J Cancer 2020;146:1503-13.

9. Paci E, Puliti D, Lopes Pegna A, et al. Mortality, survival and incidence rates in the ITALUNG randomised lung cancer screening trial. Thorax 2017;72:825-31.

10. Infante $M$, Sestini $S$, Galeone $C$, et al. Lung cancer screening with low-dose spiral computed tomography: evidence from a pooled analysis of two Italian randomized 
trials. Eur J Cancer Prev 2017;26:324-9.

11. Pastorino U, Silva M, Sestini S, et al. Prolonged lung cancer screening reduced 10-year mortality in the MILD trial: new confirmation of lung cancer screening efficacy. Ann Oncol 2019;30:1162-9.

12. Hansell DM, Bankier AA, MacMahon H, et al. Fleischner Society: glossary of terms for thoracic imaging. Radiology 2008;246:697-722.

13. Henschke CI, Yankelevitz DF, Mirtcheva R, et al. CT screening for lung cancer: frequency and significance of part-solid and nonsolid nodules. AJR Am J Roentgenol 2002;178:1053-7.

14. McWilliams A, Tammemagi MC, Mayo JR, et al. Probability of cancer in pulmonary nodules detected on first screening CT. N Engl J Med 2013;369:910-9.

15. Truong MT, Ko JP, Rossi SE, et al. Update in the evaluation of the solitary pulmonary nodule. Radiographics 2014;34:1658-79.

16. Zhan P, Xie H, Xu C, et al. Management strategy of solitary pulmonary nodules. J Thorac Dis 2013;5:824-9.

17. Ost DE, Gould MK. Decision making in patients with pulmonary nodules. Am J Respir Crit Care Med 2012;185:363-72.

18. Wahidi MM, Govert JA, Goudar RK, et al. Evidence for the treatment of patients with pulmonary nodules: when is it lung cancer?: ACCP evidence-based clinical practice guidelines (2nd edition). Chest 2007;132:94S-107S.

19. Horeweg N, van Rosmalen J, Heuvelmans MA, et al. Lung cancer probability in patients with CT-detected pulmonary nodules: a prespecified analysis of data from the NELSON trial of low-dose CT screening. Lancet Oncol 2014;15:1332-41.

20. Bankier AA, MacMahon H, Goo JM, et al. Recommendations for Measuring Pulmonary Nodules at CT: A Statement from the Fleischner Society. Radiology 2017;285:584-600.

21. Han D, Heuvelmans MA, Vliegenthart R, et al. Influence of lung nodule margin on volume- and diameter-based reader variability in CT lung cancer screening. Br J Radiol 2018;91:20170405.

22. Revel MP, Bissery A, Bienvenu M, et al. Are twodimensional CT measurements of small noncalcified pulmonary nodules reliable? Radiology 2004;231:453-8.

23. Yankelevitz DF, Reeves AP, Kostis WJ, et al. Small pulmonary nodules: volumetrically determined growth rates based on CT evaluation. Radiology 2000;217:251-6.

24. Ko JP, Berman EJ, Kaur M, et al. Pulmonary Nodules: growth rate assessment in patients by using serial CT and three-dimensional volumetry. Radiology 2012;262:662-71.

25. Oudkerk M, Devaraj A, Vliegenthart R, et al. European position statement on lung cancer screening. Lancet Oncol 2017;18:e754-66.

26. Devaraj A, van Ginneken B, Nair A, et al. Use of Volumetry for Lung Nodule Management: Theory and Practice. Radiology 2017;284:630-44.

27. Tammemagi M, Ritchie AJ, Atkar-Khattra S, et al. Predicting Malignancy Risk of Screen-Detected Lung Nodules-Mean Diameter or Volume. J Thorac Oncol 2019;14:203-11.

28. Bueno J, Landeras L, Chung JH. Updated Fleischner Society Guidelines for Managing Incidental Pulmonary Nodules: Common Questions and Challenging Scenarios. Radiographics 2018;38:1337-50.

29. Schreuder A, Jacobs C, Scholten ET, et al. Typical CT Features of Intrapulmonary Lymph Nodes: A Review. Radiol Cardiothorac Imaging 2020;2:e190159.

30. Edey AJ, Hansell DM. Incidentally detected small pulmonary nodules on CT. Clin Radiol 2009;64:872-84.

31. de Hoop B, van Ginneken B, Gietema H, et al. Pulmonary perifissural nodules on CT scans: rapid growth is not a predictor of malignancy. Radiology 2012;265:611-6.

32. Ahn MI, Gleeson TG, Chan IH, et al. Perifissural nodules seen at CT screening for lung cancer. Radiology 2010;254:949-56.

33. Schreuder A, van Ginneken B, Scholten ET, et al. Classification of CT Pulmonary Opacities as Perifissural Nodules: Reader Variability. Radiology 2018;288:867-75.

34. Mets OM, Chung K, Scholten ET, et al. Incidental perifissural nodules on routine chest computed tomography: lung cancer or not? Eur Radiol 2018;28:1095-101.

35. Snoeckx A, Reyntiens P, Desbuquoit D, et al. Evaluation of the solitary pulmonary nodule: size matters, but do not ignore the power of morphology. Insights Imaging 2018;9:73-86.

36. Farooqi AO, Cham $M$, Zhang L, et al. Lung cancer associated with cystic airspaces. AJR Am J Roentgenol 2012;199:781-6.

37. Park CM, Goo JM, Kim TJ, et al. Pulmonary nodular ground-glass opacities in patients with extrapulmonary cancers: what is their clinical significance and how can we determine whether they are malignant or benign lesions? Chest 2008;133:1402-9.

38. Walter JE, Heuvelmans MA, Yousaf-Khan U, et al. New Subsolid Pulmonary Nodules in Lung Cancer Screening: The NELSON Trial. J Thorac Oncol 2018;13:1410-4. 
39. Travis WD, Brambilla E, Noguchi M, et al. International association for the study of lung cancer/american thoracic society/european respiratory society international multidisciplinary classification of lung adenocarcinoma. J Thorac Oncol 2011;6:244-85.

40. Cohen JG, Reymond E, Lederlin M, et al. Differentiating pre- and minimally invasive from invasive adenocarcinoma using CT-features in persistent pulmonary part-solid nodules in Caucasian patients. Eur J Radiol 2015;84:738-44.

41. Lee JH, Park CM, Lee SM, et al. Persistent pulmonary subsolid nodules with solid portions of $5 \mathrm{~mm}$ or smaller: Their natural course and predictors of interval growth. Eur Radiol 2016;26:1529-37.

42. Lee SM, Park CM, Goo JM, et al. Transient part-solid nodules detected at screening thin-section CT for lung cancer: comparison with persistent part-solid nodules. Radiology 2010;255:242-51.

43. Hasegawa M, Sone S, Takashima S, et al. Growth rate of small lung cancers detected on mass CT screening. Br J Radiol 2000;73:1252-9.

44. Song YS, Park CM, Park SJ, et al. Volume and mass doubling times of persistent pulmonary subsolid nodules detected in patients without known malignancy. Radiology 2014;273:276-84.

45. Lee SM, Park CM, Goo JM, et al. Invasive pulmonary

doi: $10.21037 /$ asj-21-52

Cite this article as: Franchi P, Procaccini L, Mincuzzi E. Role of computed tomography in the diagnosis of solitary pulmonary nodule with solid component: a narrative review. AME Surg J 2022;2:29. adenocarcinomas versus preinvasive lesions appearing as ground-glass nodules: differentiation by using CT features. Radiology 2013;268:265-73.

46. van Ginneken B, Armato SG 3rd, de Hoop B, et al. Comparing and combining algorithms for computeraided detection of pulmonary nodules in computed tomography scans: The ANODE09 study. Med Image Anal 2010;14:707-22.

47. Setio AAA, Traverso A, de Bel T, et al. Validation, comparison, and combination of algorithms for automatic detection of pulmonary nodules in computed tomography images: The LUNA16 challenge. Med Image Anal 2017;42:1-13.

48. Ciompi F, Chung K, van Riel SJ, et al. Towards automatic pulmonary nodule management in lung cancer screening with deep learning. Sci Rep 2017;7:46479.

49. Chartrand G, Cheng PM, Vorontsov E, et al. Deep Learning: A Primer for Radiologists. Radiographics 2017;37:2113-31.

50. Chassagnon G, Vakalopolou M, Paragios N, et al. Deep learning: definition and perspectives for thoracic imaging. Eur Radiol 2020;30:2021-30.

51. Schreuder A, Scholten ET, van Ginneken B, et al. Artificial intelligence for detection and characterization of pulmonary nodules in lung cancer CT screening: ready for practice? Transl Lung Cancer Res 2021;10:2378-88. 